\title{
Rare anatomical variations of third molars: Two cases reported
}

\author{
Ashvini Vadane ${ }^{1, *}$, Hassaan Kazi², Amit Sangle ${ }^{3}$ \\ ${ }^{1}$ Senior Lecturer, ${ }^{2}$ PG Student, ${ }^{3}$ Professor, Dept. of Oral and Maxillofacial Surgery, M.A. Rangoonwala College of Dental Sciences and \\ Research Centre, Pune, Maharashtra, India \\ *Corresponding Author: Ashvini Vadane \\ Email: drashvinivadane@gmail.com
}

\begin{abstract}
The size of tooth and appearance are being easily noticed. The crown of the tooth is being affected by the majority of pathological variations in the morphology of tooth. Variations in the morphology of tooth have been a topic of interest to dentists since long time. ${ }^{1}$

We report here, two rare cases of four-rooted maxillary third molar and three-rooted mandibular third molar. Extraction of such type of teeth is considered to be a difficult task. We had managed extraction of these teeth with absence of any postoperative complications and teeth were being extracted in-toto.
\end{abstract}

Keywords: Maxillary third molar, Mandibular third molar, Morphological variations, Three rooted molar, Four rooted molar.

\section{Introduction}

In this article, we are reporting two rare cases .In the first case, the maxillary third molar is having four roots and in the second case, mandibular third molar is having three roots. Both these incidences are very rare. Extraction of these teeth is considered to be difficult because of abnormal root patterns. But, both cases were managed in the department of oral and maxillofacial surgery of M.A. Rangoonwala College of Dental Sciences and Research Centre, Pune. Although these teeth were having abnormal and difficult root patterns, we had extracted these teeth in-toto with no postoperative complications. Fig. 1 shows extracted maxillary third molar tooth which is having four roots whereas Fig. 2 indicates extracted mandibular third molar tooth which is having three roots.
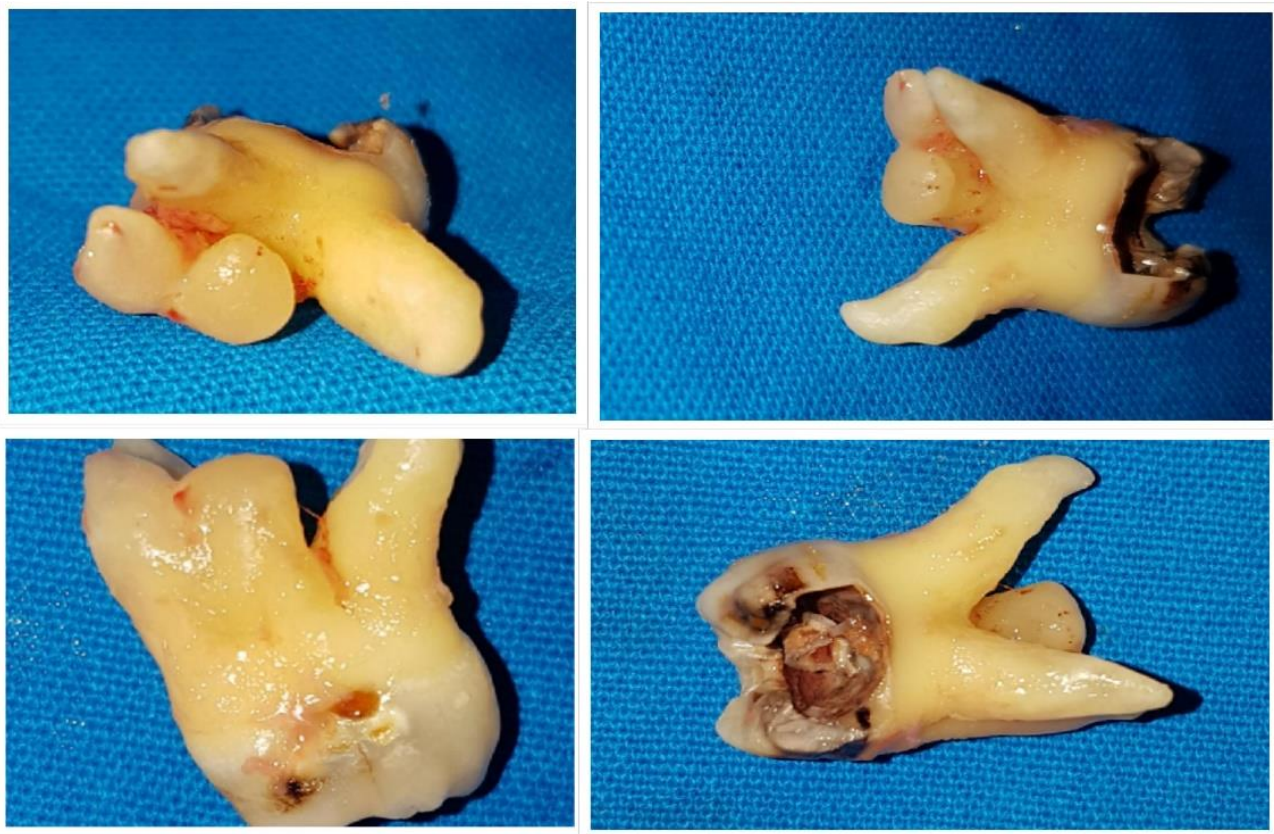

Fig. 1: Four rooted maxillary third molar 

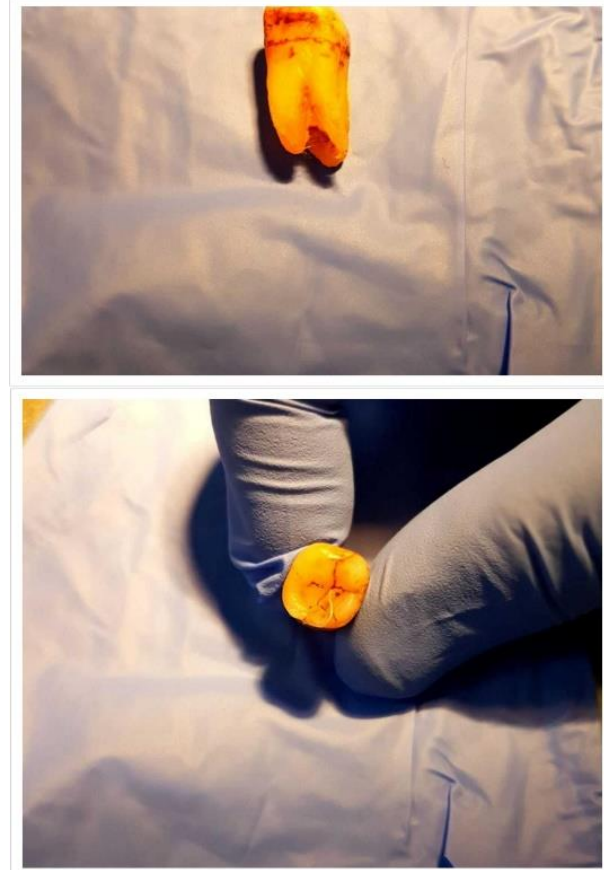

Fig. 2: Three rooted mandibular third molar

\section{Discussion}

There are various abnormalities of tooth form, like variations in number of roots, variations in form of root. Permanent maxillary peg shaped lateral incisors is the common form of abnormality seen whereas complete anodontia is the rare abnormality which is seen. ${ }^{1}$

Third molar teeth are more prone to complications as they are located posteriorly in the oral cavity and they have complicated anatomy. Because of this difficulty, extraction of third molars proves treatment of choice for many dentists. ${ }^{8}$

Third molars are also known as wisdom teeth. These third molars are more prone to postoperative problems as they are located posteriorly in the arch. They have complex anatomy and their eruption patterns are abnormal. While extracting third molars, minimal interventions are necessary and we should retain every functional component of the dental arch. Anatomy and location of mandibular third molar teeth need careful consideration because of the possibility of damage to the inferior alveolar nerve. ${ }^{8}$

\section{Conclusion}

Variations and developmental anomalies of teeth should be examined by the clinician properly for delivering the best treatment plan, i.e., it may be endodontic treatment or extraction.

\section{References}

1. Madhushankari GS. Emphasizing a new developmental variation of the Mandibular Molars - A Mermaid in Dentistry? J Clin Diagn Res 2011;5(2):402-403.

2. Denzil Valerian Albuquerque. A New Anatomically Based Nomenclature for the Roots and Root Canals--------Part 2: Mandibular Molars. Int J Dent Volume 2012, Article ID 814789

3. Jamil $\mathrm{G}$ et al. $3^{\mathrm{Rd}}$ Molar variations via radiograph. Biology,
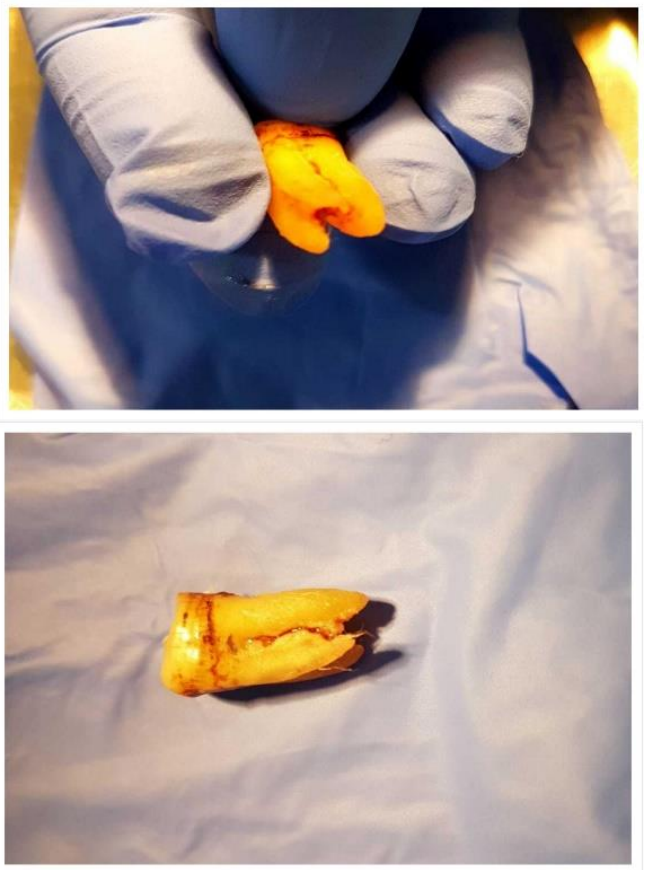

Engineering and Medicine. 2017;2(3):1-6.

4. Pradeep Jain et al. Endodontic management of maxillary third molar with MB2 (vertucci type IV) canal configuration diagnosed with cone beam computed tomography - a case report. Clujul Med, 2017;90(4):459-463.

5. P Vishnu Unni, M Kundabala. Endodontic Therapy of Maxillary Third Molar with Supernumerary Root with Four Root Canals-A Rare Case. Biomed J Sci \& Tech Res 2017;1(4).

6. Mohammadi Z, Jafarzadeh H, Shalavi S, Bandi S , Patil SG. Root and Root Canal Morphology of Human Third Molar Teeth. J Contemp Dent Pract 2015;16(4):310-313.

7. Benjamin Briseno Marroquin. Morphology of the Physiological Foramen: I. Maxillary and Mandibular Molars. $J$ Endod 2004;30(5).

8. Sandra Sagar. Variations in anatomy and position of mandibular third molars in south Indian population. $J$ Pharm Sci Res. 2015;7(6):385-386.

9. Maryam Kuzekanani. Root and Canal Morphology of Mandibular Third Molars in an Iranian Population. J Dent Res, Dent Clin, Dent Prospects 2012;6(3):85-88.

10. Hany Mohamed Ali Ahmed. Management of third molar teeth from an endodontic perspective. Eur Gen Dent 2012;I(3):

11. Neeraja Ramamurthy, Ila Srinivasan. Bilateral three-rooted primary lower molars. Indian J Dent Res 2012;23:700

12. Vinay Kumar Bhardwaj. Additional Root in the Mandibular First Molar - A Rare Case Report. J Dent Health, Oral Disor Ther 2016;5(4):00162.

13. Woelfel JB, Scheid RC. Dental Anatomy: Its Relevance to Dentistry. 5th ed. USA: Williams and Wilkins; 1997.

14. Winter GB, Brook AH. Enamel hypoplasia and anomalies of the teeth. Dent Clin North Am 1975;9:3-24.

15. F. B. Barletta, S. R. Dotto, M. S. Reis, R. Ferreira, and R. M. Travassos, "Mandibular molar with five root canals," Aust Endod J, 2008;34(3):129-132.

How to cite this article: Vadane A, Kazi H, Sangle A. Rare anatomical variations of third molars: Two cases reported. Int Dent J Student's Res. 2018;6(4):79-80. 